\title{
Ketalization of Phosphonium Ions by 1,4-Dioxane: Selective Detection of the Chemical Warfare Agent Simulant DMMP in Mixtures Using Ion/Molecule Reactions
}

\author{
Hao Chen, Xubin Zheng, and R. Graham Cooks \\ Department of Chemistry, Purdue University, West Lafayette, Indiana, USA
}

\begin{abstract}
Phosphonium ions $\mathrm{CH}_{3} \mathrm{P}(\mathrm{O}) \mathrm{OCH}_{3}^{+}$(93 Th) and $\mathrm{CH}_{3} \mathrm{OP}(\mathrm{O}) \mathrm{OCH}_{3}^{+}$(109 Th) react with 1,4dioxane to form unique cyclic ketalization products, 1,3,2-dioxaphospholanium ions. By contrast, a variety of other types of ions having multiple bonds, including the acylium ions $\mathrm{CH}_{3} \mathrm{CO}^{+}(43 \mathrm{Th}), \mathrm{CH}_{3} \mathrm{OCO}^{+}(59 \mathrm{Th}),\left(\mathrm{CH}_{3}\right)_{2} \mathrm{NCO}^{+}(72 \mathrm{Th})$, and $\mathrm{PhCO}^{+}(105 \mathrm{Th})$, the iminium ion $\mathrm{H}_{2} \mathrm{C}=\mathrm{NHC}_{2} \mathrm{H}_{5}^{+}(58 \mathrm{Th})$ and the carbosulfonium ion $\mathrm{H}_{2} \mathrm{C}=\mathrm{SC}_{2} \mathrm{H}_{5}^{+}(75 \mathrm{Th})$ do not react with 1,4-dioxane under the same conditions. The characteristic ketalization reaction can also be observed when $\mathrm{CH}_{3} \mathrm{P}(\mathrm{OH})\left(\mathrm{OCH}_{3}\right)_{2}^{+}$, viz. protonated dimethyl methylphosphonate (DMMP), collides with 1,4-dioxane, as a result of fragmentation to yield the reactive phosphonium ion $\mathrm{CH}_{3} \mathrm{P}(\mathrm{O}) \mathrm{OCH}_{3}^{+}(93 \mathrm{Th})$. This novel ion/molecule reaction is highly selective to phosphonium ions and can be applied to identify DMMP selectively in the presence of ketone, ester, and amide compounds using a neutral gain MS/MS scan. This method of DMMP analysis can be applied to aqueous solutions using electrospray ionization; it shows a detection limit in the low $\mathrm{ppb}$ range and a linear response over the range 10 to $500 \mathrm{ppb}$. (J Am Soc Mass Spectrom 2003, 14, 182-188) @ 2003 American Society for Mass Spectrometry
\end{abstract}

$\mathrm{O}$ rganophosphorus esters and related compounds have been used widely as pesticides, fertilizers, and even warfare agents. Detection of organophosphorus ester compounds is therefore an important issue that needs to be addressed because of obvious concerns for civilian safety. Because these compounds might occur in low levels together with many extraneous organic compounds, their detection represents a great challenge and a highly selective and sensitive analytical method is needed. Mass spectrometric methods have been used in the detection of organophosphorus compounds [1-3] and tandem mass spectrometry has been employed to improve selectivity and sensitivity $[4,5]$. An alternative approach to obtain high selectivity is the use of characteristic ion/molecule reactions as structural probes which would be especially useful for mixture analysis [6, 7]. Since organophosphonates and related compounds containing phosphoryl groups are used as chemical warfare agents, studies which explore characteristic ion/molecule reactions of either phosphonium ions $(\mathrm{RO})_{2} \mathrm{P}(\mathrm{O})^{+}$[or $\left.(\mathrm{RO}) \mathrm{R}^{\prime} \mathrm{P}(\mathrm{O})^{+}\right]$or of neutral organophosphonate molecules $(\mathrm{RO})_{2} \mathrm{R}^{\prime} \mathrm{P}(\mathrm{O})$ could be of great value.

Published online January 27, 2003

Address reprint requests to Dr. R. G. Cooks, Department of Chemistry, Purdue University, 506 Oval Drive, West Lafayette, IN 47907-1393, USA.

E-mail: cooks@purdue.edu
Ion/molecule reactions of the phosphonium ion $\mathrm{CH}_{3} \mathrm{OP}(\mathrm{O}) \mathrm{OCH}_{3}^{+}(109 \mathrm{Th}, 1 \mathrm{Th}=1 \mathrm{da} / \mathrm{u}$ charge [8]) and trimethyl phosphite (TMPI) have been reported by ion cyclotron resonance mass spectrometry (ICR-MS) [9]. It was shown that the principal reaction of $\mathrm{CH}_{3} \mathrm{OP}(\mathrm{O}) \mathrm{OCH}_{3}^{+}(109 \mathrm{Th})$ with TMPI leads to phosphenium ions $\mathrm{P}\left(\mathrm{OCH}_{3}\right)_{2}^{+}(93 \mathrm{Th})$ and neutral trimethyl phosphate, together with trace amounts of tetramethyl phosphonium ions $\mathrm{P}\left(\mathrm{OCH}_{3}\right)_{4}^{+}(155 \mathrm{Th})$ and $\mathrm{CH}_{3} \mathrm{OP}(\mathrm{O})$. Morizur et al. found using an ion trap mass spectrometer that phosphonium ions $\mathrm{CH}_{3} \mathrm{OP}(\mathrm{O}) \mathrm{OCH}_{3}^{+}(109 \mathrm{Th})$ formed by electron ionization of neutral TMPI are subject to nucleophilic attack from residual water in the ion trap to give stable adducts [10]. They also studied the gas-phase reactivity of phosphonium ions $(\mathrm{HO})_{2} \mathrm{P}(\mathrm{O})^{+}(81 \mathrm{Th})$ towards methanol, both experimentally and theoretically. The phosphonium ions $(\mathrm{HO})_{2} \mathrm{P}(\mathrm{O})^{+}(81 \mathrm{Th})$ react with methanol to yield protonated trimethyl phosphate $\mathrm{P}(\mathrm{OH})\left(\mathrm{OCH}_{3}\right)_{3}^{+}(141 \mathrm{Th})$ via a sequential methanol addition/water elimination mechanism [11]. They further reported that the phosphonium ion $\mathrm{CH}_{3} \mathrm{OP}(\mathrm{O}) \mathrm{OCH}_{3}^{+}$(109 Th) forms adducts with benzene and also reacts by charge exchange [12]. Operti et al. observed a self-condensation ion/molecule reaction of dimethyl phosphonate in the ion trap, which produces the protonated dimer as the only abundant product [13]. Kenttämaa found that phosphonium ions $\mathrm{CH}_{3} \mathrm{P}(\mathrm{O}) \mathrm{OCH}_{3}^{+}(93 \mathrm{Th})$ react exclusively with cis-1,2- 


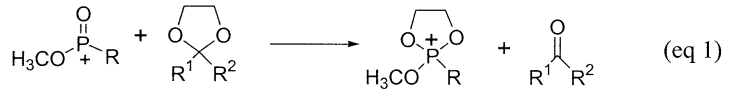

$$
\begin{aligned}
& \mathrm{R}=\mathrm{CH}_{3}, \mathrm{OCH}_{3} \\
& \stackrel{+}{\mathrm{R}-\mathrm{C}=\mathrm{O}}+\underset{\mathrm{R}^{1}}{\mathrm{O}_{\mathrm{R}^{2}}^{\mathrm{O}}} \longrightarrow \underset{\mathrm{R}}{\mathrm{O}_{+}^{\mathrm{O}}}+\underset{\mathrm{R}^{1}}{\mathrm{H}_{\mathrm{R}^{2}}} \quad \text { (eq 2) }
\end{aligned}
$$

cyclohexanediol to form $\mathrm{CH}_{3} \mathrm{P}(\mathrm{OH})_{2} \mathrm{OCH}_{3}^{+}$(111 Th) by water abstraction [14]. Related studies [15-17] demonstrated that the long-lived radical cations of small organophosphates and trimethylphosphine oxide isomerize spontaneously to distonic ions which were characterized using collision-induced dissociation (CID). The reactions of dimethyl methylphosphonate (DMMP) with a variety of anions such as amide, hydrogen sulfide, methoxide, and fluoride have been examined by Lum and Grabowski [18]. These reactions involve proton transfer, reductive elimination, and nucleophilic substitution at carbon or phosphorus. Furthermore, ion/molecule reactions of phosphonate compounds with alkoxide reactants have also been explored by Tabet and diagnostic product ions $[\mathrm{M}-\mathrm{R}]^{-}$and $[\mathrm{M}-\mathrm{R}+14]^{-}$( $\mathrm{R}$ is the alkyl group of the phosphonate) were observed $[19,20]$.

An earlier study from this laboratory reported the formation of cyclic 1,3,2-dioxaphospholanium ions in the ketalization reactions of phosphonium ions $\mathrm{CH}_{3} \mathrm{P}(\mathrm{O}) \mathrm{OCH}_{3}^{+}(93 \mathrm{Th})$ and $\mathrm{CH}_{3} \mathrm{OP}(\mathrm{O}) \mathrm{OCH}_{3}^{+}(109 \mathrm{Th})$ with 1,3-dioxolane (eq 1 in Scheme 1) [21]. The ketalization reaction involved transacetalization in which the protecting group of 1,3-dioxolane, the oxirane $\mathrm{CH}_{2} \mathrm{CH}_{2} \mathrm{O}$ moiety, was transferred onto the phosphoryl group, producing the cyclic 1,3,2-dioxaphospholanium ion and releasing the free ketone. This reaction is analogous to reactions of acylium ions $\mathrm{RCO}^{+}$and cyclic acetals or ketals like 1,3-dioxolane (eq 2 in Scheme 1) by the gas-phase transacetalization mechanism initially discovered by Eberlin et al. [22-26]. In Eberlin reactions, structures of product ions have been clearly determined by their fragmentation patterns [21, 22] and by isotopelabeling experiments [27] and transacetalization mechanisms are well established. Not only have the reactions been studied extensively but these reactions have already found analytical and synthetic applications [2832]. For instance, these transacetalization reactions can be used to characterize functional group in either ionic or neutral reactants, revealing specific structural details or distinguishing them from isomers. The gas phase synthesis of several heterocycles has been performed via related transacetalizations with other gaseous amphoteric cations such as sulfinyl [33, 34], silylium [35], and borinium [36, 37] ions.

We report here on the reactions of phosphonium ions $\mathrm{CH}_{3} \mathrm{P}(\mathrm{O}) \mathrm{OCH}_{3}^{+}\left(93 \mathrm{Th}\right.$ ) and $\mathrm{CH}_{3} \mathrm{OP}(\mathrm{O}) \mathrm{OCH}_{3}^{+}(109$ Th) with 1,4-dioxane. The study is motivated by the wish to discover characteristic ion/molecule reactions of phosphoryl-containing ions and to apply these reactions to the detection of DMMP, a common chemical warfare agent simulant.

\section{Experimental}

Ion/molecule reactions were carried out on a Finnigan TSQ-70 triple quadrupole mass spectrometer (Thermo Finnigan, San Jose, CA) with the ion source and manifold temperatures maintained at 150 and $70{ }^{\circ} \mathrm{C}$, respectively. The ions $\mathrm{CH}_{3} \mathrm{P}(\mathrm{O}) \mathrm{OCH}_{3}^{+}$(or $\mathrm{CH}_{3} \mathrm{OP}(\mathrm{O}) \mathrm{OCH}_{3}^{+}$), $\mathrm{CH}_{3} \mathrm{CO}^{+}$(or $\left.\mathrm{CH}_{3} \mathrm{OCO}^{+}\right),\left(\mathrm{CH}_{3}\right)_{2} \mathrm{NCO}^{+}, \mathrm{PhCO}^{+}$, $\mathrm{H}_{2} \mathrm{C}=\mathrm{NHC}_{2} \mathrm{H}_{5}^{+}$, and $\mathrm{H}_{2} \mathrm{C}=\mathrm{SC}_{2} \mathrm{H}_{5}^{+}$ions were generated by $70 \mathrm{eV}$ electron ionization (EI) of DMMP (Lancaster, Pelham, NH) [14], methyl acetate [22], N,N-dimethyl formamide (Baker Analyzed Reagent, Philipsburg, NJ) [22], butyrophenone (Aldrich, Milwaukee, WI), diethyl amine (Aldrich) [38] and diethyl disulfide (Sigma, St. Louis, MO) [25], respectively. Ions $\mathrm{CH}_{3} \mathrm{P}(\mathrm{OH})\left(\mathrm{OCH}_{3}\right)_{2}^{+}$ and $\left(\mathrm{CH}_{3} \mathrm{O}\right)_{3} \mathrm{P}(\mathrm{OH})^{+}$were generated separately by isobutane chemical ionization of DMMP and trimethyl phosphate. Ion/molecule reactions were performed by mass selection of precursor ions in Q1, reaction with neutral reagent in $\mathrm{Q} 2$, and mass analysis using $\mathrm{Q} 3$ to monitor product ions. 1,4-Dioxane (Aldrich), 1,4-dioxane- $\mathrm{d}_{8}$ (Cambridge Isotope Laboratories, Andover, MA) or a mixture of 1,4-dioxane and 1,4-dioxane- $\mathrm{d}_{8}(1: 1$ by volume) was used as the collision gas and the optimized collision energy was found to be nominal $0 \mathrm{eV}$. Neutral gain MS/MS spectra were recorded by selecting a mass-gain value and scanning Q1 and Q3 simultaneously at the same rate.

Quantitation and detection limit experiments on aqueous solutions containing DMMP were carried out on a Finnigan TSQ 700 triple quadrupole mass spectrometer (Thermo Finnigan) with an electrospray ionization (ESI) source. DMMP standard solutions $\left(\mathrm{H}_{2} \mathrm{O}\right.$ : $\mathrm{CH}_{3} \mathrm{OH}: \mathrm{CH}_{3} \mathrm{COOH}=200: 200: 1$ by volume) were injected at a flow of $20 \mu \mathrm{l} / \mathrm{min}$ using a syringe pump (Harvard Apparatus, Holliston, MA) using an ESI voltage of $5 \mathrm{kV}$. Neutral gain MS/MS spectra were recorded in the same way as in TSQ 70.

\section{Results and Discussion}

Ion/molecule reactions of $\mathrm{CH}_{3} \mathrm{P}(\mathrm{O}) \mathrm{OCH}_{3}^{+}$(93 Th) and $\mathrm{CH}_{3} \mathrm{OP}(\mathrm{O}) \mathrm{OCH}_{3}^{+}$(109 Th) with 1,4-dioxane occur readily and yield product ions of 137 and $153 \mathrm{Th}$, respectively. The increment of $44 \mathrm{Th}$ in mass/charge corresponds to the addition of the moiety $\mathrm{CH}_{2} \mathrm{CH}_{2} \mathrm{O}$, which is confirmed by the fact that the increase is $48 \mathrm{Th}$ if 1,4-dioxane- $\mathrm{d}_{8}$ is used instead of 1,4-dioxane (Table 1). Therefore, the product ions of 137 and 153 Th should be 1,3,2-dioxaphospholanium ions, which surprisingly are exactly the same ions as those generated from the Eberlin ketalization reaction of $\mathrm{CH}_{3} \mathrm{P}(\mathrm{O}) \mathrm{OCH}_{3}^{+}(93 \mathrm{Th})$ and $\mathrm{CH}_{3} \mathrm{OP}(\mathrm{O}) \mathrm{OCH}_{3}^{+}$(109 Th) with 1,3-dioxolane (eq 1 in Scheme 1) [21]. Obviously, the former reaction has a different mechanism from the latter. 
Table 1. Major ionic products of ion/molecule reactions with 1, 4-dioxane and 1, 4-dioxane- $\mathrm{d}_{8}$

\begin{tabular}{|c|c|c|c|c|c|}
\hline \multicolumn{2}{|l|}{ Reagent } & \multicolumn{4}{|c|}{ Products, Th (relative abundance) ${ }^{a}$} \\
\hline lons & Neutral & $\begin{array}{l}\text { Ketalization } \\
\text { product }\end{array}$ & $\begin{array}{c}\text { Proton transfer and hydride } \\
\text { (or deuterium) abstraction } \\
\text { product }\end{array}$ & Adduct & Other ions \\
\hline \multirow[t]{2}{*}{$\mathrm{CH}_{3} \mathrm{P}(\mathrm{O}) \mathrm{OCH}_{3}^{+}(93 \mathrm{Th})$} & 1, 4-dioxane & $137(100)$ & $89(23), 87(19)$ & $-{ }^{b}$ & $63,79,111,177$ \\
\hline & 1, 4-dioxane- $d_{8}$ & $141(100)$ & $97(31), 94(37)$ & $189(6)$ & $63,79,111,193$ \\
\hline \multirow[t]{2}{*}{$\mathrm{CH}_{3} \mathrm{OP}(\mathrm{O}) \mathrm{OCH}_{3}{ }^{+}(109 \mathrm{Th})$} & 1, 4-dioxane & $153(100)$ & $89(27), 87$ (39) & - & $59,79,127,177,215$ \\
\hline & 1, 4-dioxane- $d_{8}$ & $157(100)$ & $97(35), 94(46)$ & - & $63,79,129,193$ \\
\hline \multirow[t]{2}{*}{$\mathrm{CH}_{3} \mathrm{P}(\mathrm{OH})\left(\mathrm{OCH}_{3}\right)^{+}(125 \mathrm{Th})$} & 1, 4-dioxane & $137(37)$ & $89(7), 87(7)$ & $213(100)$ & 93,177 \\
\hline & 1, 4-dioxane- $d_{8}$ & 141 (49) & $97(11), 94(7)$ & $221(100)$ & $93,183,193$ \\
\hline \multirow[t]{2}{*}{$\left(\mathrm{CH}_{3} \mathrm{O}\right)_{3} \mathrm{P}(\mathrm{OH})^{+}(141 \mathrm{Th})$} & 1, 4-dioxane & $153(20)$ & $89(3), 87(5)$ & $229(100)$ & $109,127,158,177,199$ \\
\hline & 1, 4-dioxane- $d_{8}$ & $157(28)$ & $97(1), 94(5)$ & $237(100)$ & $109,193,199,229$ \\
\hline \multirow[t]{2}{*}{$\mathrm{CH}_{3} \mathrm{CO}^{+}(43 \mathrm{Th})$} & 1, 4-dioxane & - & $89(100)^{c}$ & - & $74,75,88$ \\
\hline & 1, 4-dioxane- $d_{8}$ & - & $97(100)^{c}$ & - & $75,89,96$ \\
\hline \multirow[t]{2}{*}{$\mathrm{CH}_{3} \mathrm{OCO}^{+}(59 \mathrm{Th})$} & 1, 4-dioxane & - & $89(100)^{c}$ & - & $31,43,73$ \\
\hline & 1, 4-dioxane-d 8 & - & - & - & $31,43,63,89$ \\
\hline \multirow[t]{2}{*}{$\left(\mathrm{CH}_{3}\right)_{2} \mathrm{NCO}^{+}(72 \mathrm{Th})$} & 1, 4-dioxane & - & - & - & $44,58,73$ \\
\hline & 1, 4-dioxane- $d_{8}$ & - & $97(100)^{c}$ & - & $44,58,73,96$ \\
\hline \multirow[t]{2}{*}{$\mathrm{PhCO}^{+}(105 \mathrm{Th})$} & 1, 4-dioxane & - & - & - & $51,53,77,150$ \\
\hline & 1, 4-dioxane- $d_{8}$ & - & $97(100)^{c}, 94(73)$ & - & $51,53,77,125$ \\
\hline \multirow[t]{2}{*}{$\mathrm{CH}_{2}=\mathrm{SEt}^{+}(75 \mathrm{Th})$} & 1, 4-dioxane & - & $89(100), 87(59)$ & - & 47,177 \\
\hline & 1, 4-dioxane- $d_{8}$ & - & - & - & 46,47 \\
\hline \multirow[t]{2}{*}{$\mathrm{CH}_{2}=\mathrm{NHEt}^{+}(58 \mathrm{Th})$} & 1, 4-dioxane & - & $89(100)^{c}$ & - & 30,74 \\
\hline & 1, 4-dioxane- $d_{8}$ & - & $97(100)^{c}$ & - & 30,74 \\
\hline
\end{tabular}

apercentage abundance relative to the base peak, excluding the reagent ion and other ions.

${ }^{b}$ Not observed.

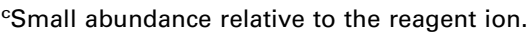

As proposed in Scheme 2, the phosphonium ion first forms an intermediate adduct 1 with the neutral 1,4dioxane molecule. Ring opening of the intermediate 1 is proposed to occur simultaneously with 1,2-hydride migration to give rise to intermediate 2 . Recyclization of the intermediate 2 and elimination of acetaldehyde yields a cyclic 1,3,2-dioxaphospholanium product ion 3 . Overall, the phosphonium ion is ketalized by 1,4dioxane. Typical product-ion spectra for mass-selected $\mathrm{CH}_{3} \mathrm{P}(\mathrm{O}) \mathrm{OCH}_{3}^{+}$(93 Th) reacting with 1,4-dioxane and 1,4-dioxane- $\mathrm{d}_{8}$ are shown in Figure $1 \mathrm{a}$ and $\mathrm{b}$. It can be seen that 1,3,2-dioxaphospholanium ions at 137 and 141 Th, respectively, are the main products in both cases. In Figure 1a, the ion $\mathrm{CH}_{3} \mathrm{P}(\mathrm{OH})^{+}(63 \mathrm{Th})$ arises from the fragmentation of $\mathrm{CH}_{3} \mathrm{P}(\mathrm{O}) \mathrm{OCH}_{3}^{+}(93 \mathrm{Th}$ ) by loss of formaldehyde upon collision [39]. The reaction of $\mathrm{CH}_{3} \mathrm{P}(\mathrm{O}) \mathrm{OCH}_{3}^{+}(93 \mathrm{Th})$ with water, present in the collision cell, yields the peak at $111 \mathrm{Th}$, which fragments

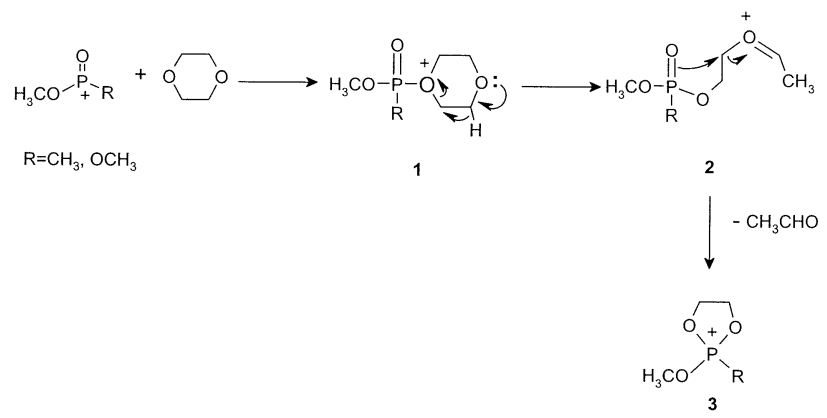

Scheme 2

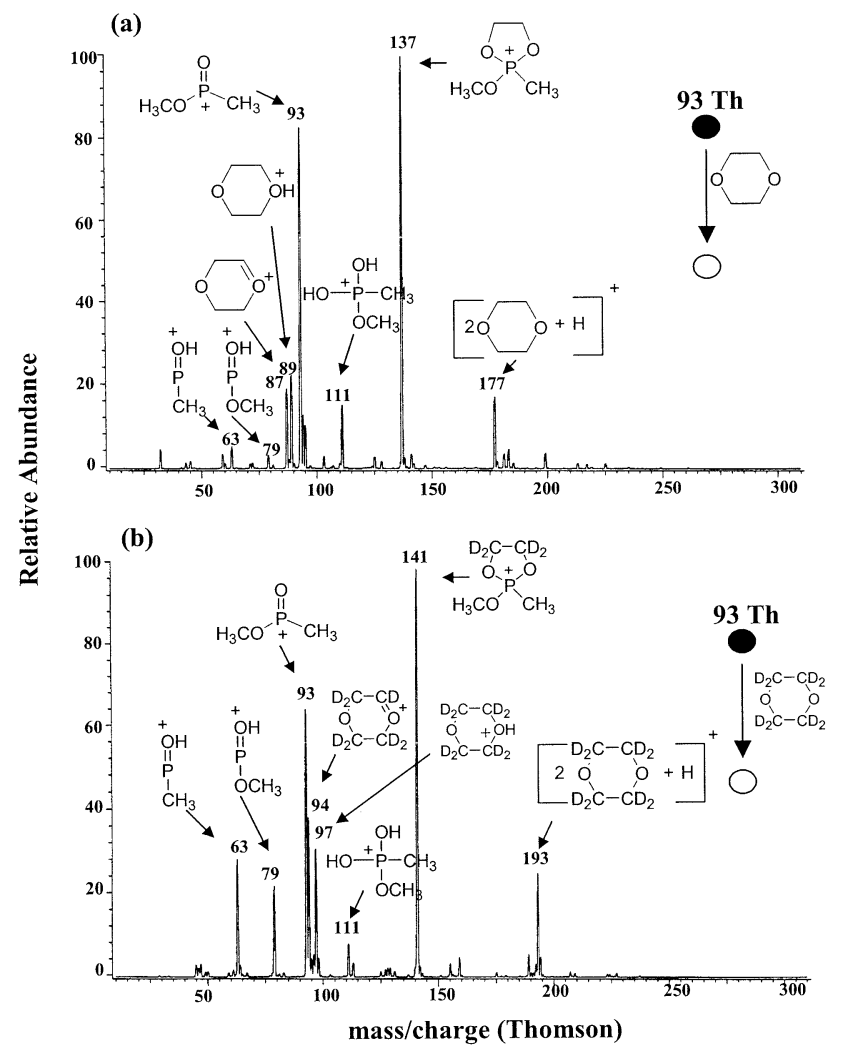

Figure 1. Product ion mass spectra showing ion/molecule reactions of $\mathrm{CH}_{3} \mathrm{P}(\mathrm{O}) \mathrm{OCH}_{3}^{+}(93 \mathrm{Th})$ at nominally zero kinetic energy. (a) Reaction with 1,4-dioxane to give $137 \mathrm{Th}$ as the main product ion; (b) reaction with 1,4-dioxane- $\mathrm{d}_{8}$ to give $141 \mathrm{Th}$ as the main product ion. 


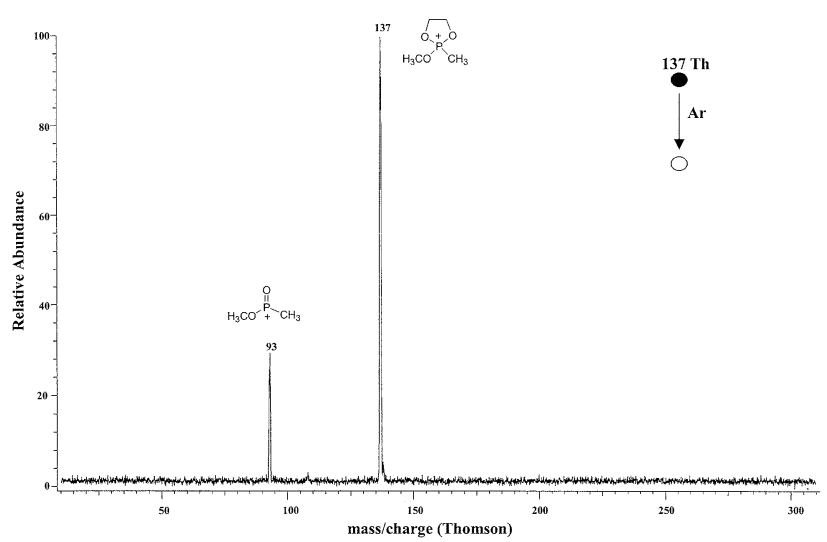

Figure 2. CID spectrum of 1,3,2-dioxaphospholanium ion (137 Th). The only fragment ion observed is $\mathrm{CH}_{3} \mathrm{P}(\mathrm{O}) \mathrm{OCH}_{3}^{+}(93 \mathrm{Th})$.

to $\mathrm{CH}_{3} \mathrm{OP}(\mathrm{OH})^{+}$(79 Th) by the loss of methanol. In addition, the protonated 1,4-dioxane monomer and dimer appear at 89 and $197 \mathrm{Th}$, probably as a result of proton transfer [36, 37] between 1,4-dioxane and the ions $\mathrm{CH}_{3} \mathrm{P}(\mathrm{OH})^{+}(63 \mathrm{Th})$ or $\mathrm{CH}_{3} \mathrm{OP}(\mathrm{OH})^{+}$(79 Th). The formation of ion $87 \mathrm{Th}$ is probably due to hydride abstraction from neutral 1,4-dioxane rather than $\mathrm{H}_{2}$ loss from protonated 1,4-dioxane. The CID spectrum of protonated 1,4-dioxane ( $89 \mathrm{Th})$ shows only fragment ion 45 Th by loss of acetaldehyde, but no fragment ion $87 \mathrm{Th}$. These assignments are consistent with the corresponding deuterated ion peaks seen in Figure 1b. Table 1 summarizes the major product ions from the ion/ molecule reactions with 1,4-dioxane and 1,4-dioxane- $\mathrm{d}_{8}$.

The ion 1,3,2-dioxaphospholanium ion (137 Th) is also produced in chemical ionization of DMMP using 1,4-dioxane as the reagent gas. The CID spectrum of the 1,3,2-dioxaphospholanium ion (137 Th) in Figure 2 illustrates that it fragments exclusively back to give $\mathrm{CH}_{3} \mathrm{P}(\mathrm{O}) \mathrm{OCH}_{3}^{+}$(93 Th). Correspondingly, in solution, 1,3,2-dioxaphospholanes are often hydrolyzed or photolyzed back to the initial phosphonium ions [21, 40]. This provides additional evidence for the structure of the 1,3,2-dioxaphospholanium ion (137 Th). Table 2 also lists the CID products of other 1,3,2-dioxaphospholanium ions formed via chemical ionization of DMMP. Note that these data refer to use of 1,4-dioxane or 1,4-dioxane- $\mathrm{d}_{8}$ as reagent gases.

The reactivity of other types of ions with 1,4-dioxane or 1,4-dioxane- $\mathrm{d}_{8}$ was also investigated. Test ions were acylium ions $\mathrm{CH}_{3} \mathrm{CO}^{+}(43 \mathrm{Th}), \mathrm{CH}_{3} \mathrm{OCO}^{+}$(59 Th), $\left(\mathrm{CH}_{3}\right)_{2} \mathrm{NCO}^{+}(72 \mathrm{Th})$, and $\mathrm{PhCO}^{+}(105 \mathrm{Th})$, iminium ions $\mathrm{H}_{2} \mathrm{C}=\mathrm{NHC}_{2} \mathrm{H}_{5}^{+}$(58 Th) and carbosulfonium ion $\mathrm{H}_{2} \mathrm{C}=\mathrm{SC}_{2} \mathrm{H}_{5}^{+}$(75 Th). The reason why these ions were examined is that they can undergo transacetalization with 1,3-dioxolane $[14,22,25,27]$ in a reaction that parallels that of phosphonium ions and they represent types of ions that might interfere during the detection of chemical warfare agents in practice. None of these ions was found to undergo the Eberlin reaction with 1,4dioxane or 1,4-dioxane- $\mathrm{d}_{8}$ under the conditions used in this study although proton transfer and hydride (or
Table 2. CID product ions of 1, 3, 2-dioxaphospholanium ions

\begin{tabular}{ccc}
\hline Precursor ions & $\begin{array}{c}\text { Products, } \mathrm{m} / \mathrm{z} \\
\text { (relative abundance) }^{\mathrm{a}}\end{array}$ \\
\hline \hline & $(137 \mathrm{Th})^{\mathrm{b}}$ & $93(100)$ \\
& $(141 \mathrm{Th})^{\mathrm{c}}$ & $93(100)$ \\
& $(153 \mathrm{Th})^{\mathrm{b}}$ & $109(100), 125(43)$ \\
& $(153 \mathrm{Th})^{\mathrm{c}}$ & $109(100), 129(27)$ \\
& & \\
\hline
\end{tabular}

aPercentage abundance relative to the base peak, excluding the precursor ions.

bProduced in chemical ionization of DMMP using 1, 4-dioxane as the reagent gas.

'Produced in chemical ionization of DMMP using 1, 4-dioxane- $d_{8}$ as the reagent gas.

deuterium) abstraction does occur in some cases (Table 1). This result is consistent with and extends the observation of Moraes et al. [27] that 1,4-dioxane is completely unreactive toward transacetalization with acylium ions $\mathrm{CH}_{2}=\mathrm{CHCO}^{+}$. It is evident that ketalization by 1,4-dioxane is highly selective for phosphonium ions. The selectivity will be extremely important for the detection of DMMP, a common simulant of chemical warfare agents, in complex matrices like air that can contain various components such as ketones, esters and amides.

Reactions of the protonated DMMP ions, $\mathrm{CH}_{3} \mathrm{P}(\mathrm{OH})\left(\mathrm{OCH}_{3}\right)_{2}^{+}$(125 Th), formed from isobutane chemical ionization with 1,4-dioxane, have also been investigated. Figure 3a illustrates the product ion spectrum. Interestingly, the putative 1,3,2-dioxaphospholanium ions (137 Th) can be observed, probably because the fragmentation of $\mathrm{CH}_{3} \mathrm{P}(\mathrm{OH})\left(\mathrm{OCH}_{3}\right)_{2}^{+}(125 \mathrm{Th})$ occurs and the fragment ions $\mathrm{CH}_{3} \mathrm{P}(\mathrm{O}) \mathrm{OCH}_{3}^{+}(93 \mathrm{Th}$ ) react with 1,4-dioxane subsequently. As expected, the protonated trimethyl phosphate ions $\left(\mathrm{CH}_{3} \mathrm{O}\right)_{3} \mathrm{P}(\mathrm{OH})^{+}(141$ Th), structurally similar to $\mathrm{CH}_{3} \mathrm{P}(\mathrm{OH})\left(\mathrm{OCH}_{3}\right)_{2}^{+}(125 \mathrm{Th})$, also undergo the ketalization reaction with 1,4-dioxane (Table 1). A possible route of the formation of 1,3,2dioxaphospholanium ions (137 Th) from $\mathrm{CH}_{3} \mathrm{P}(\mathrm{OH})\left(\mathrm{OCH}_{3}\right)_{2}^{+}(125 \mathrm{Th})$ is shown in Scheme 3. The net mass/charge gain from $\mathrm{CH}_{3} \mathrm{P}(\mathrm{OH})\left(\mathrm{OCH}_{3}\right)_{2}^{+}(125$ $\mathrm{Th})$ to the product ion $(137 \mathrm{Th})$ in the ketalization reaction with 1,4-dioxane is $12 \mathrm{Th}$. This is expected to shift to 16 Th when 1,4-dioxane- $\mathrm{d}_{8}$ is used as the collision gas. As illustrated in Figure 3b, the doublet peaks at 137 and 141 Th appear with identical abundances while the ions $\mathrm{CH}_{3} \mathrm{P}(\mathrm{OH})\left(\mathrm{OCH}_{3}\right)_{2}^{+}(125 \mathrm{Th})$ react with a mixture of 1,4-dioxane and 1,4-dioxane- $\mathrm{d}_{8}(1: 1$ by volume). The capability of the ions $\mathrm{CH}_{3} \mathrm{P}(\mathrm{OH})\left(\mathrm{OCH}_{3}\right)_{2}^{+}$ $(125 \mathrm{Th})$ to react with 1,4-dioxane to produce the characteristic 1,3,2-dioxaphospholanium ions (137 Th) should facilitate the detection of DMMP since it is easier to identify DMMP from its protonated molecular ion than its fragment ions. 


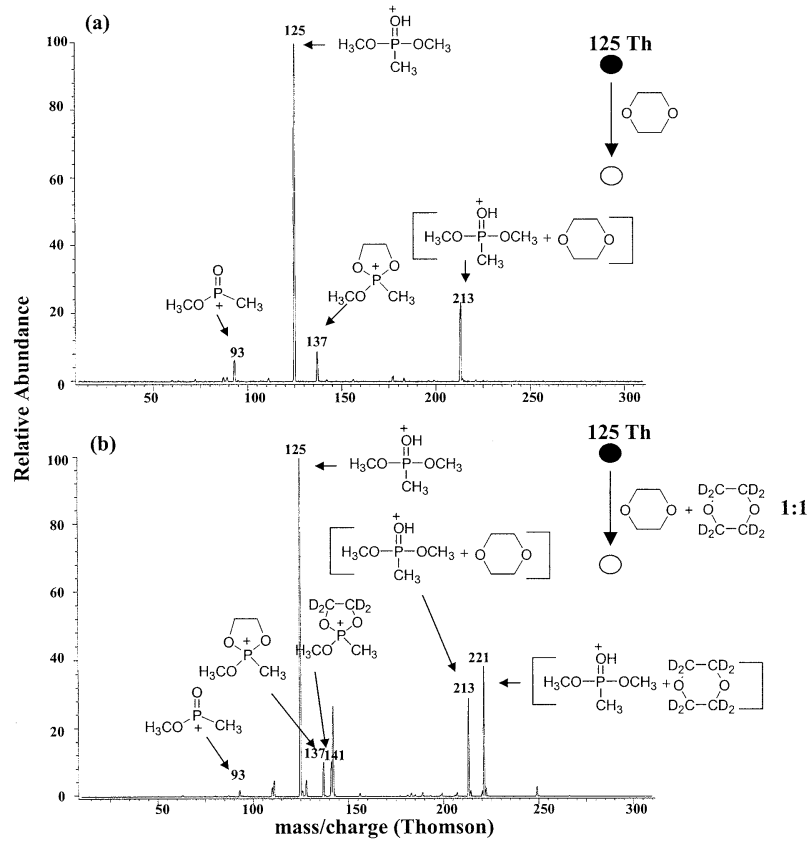

Figure 3. Product ion mass spectra showing ion/molecule reactions of $\mathrm{CH}_{3} \mathrm{P}(\mathrm{OH})\left(\mathrm{OCH}_{3}\right)_{2}^{+}(125 \mathrm{Th})$ at nominally zero kinetic energy. (a) Reaction with 1,4-dioxane. Peak $137 \mathrm{Th}$ is produced probably because fragmentation of $\mathrm{CH}_{3} \mathrm{P}(\mathrm{OH})\left(\mathrm{OCH}_{3}\right)_{2}^{+}(125 \mathrm{Th})$ occurs and the fragment ion $\mathrm{CH}_{3} \mathrm{P}(\mathrm{O}) \mathrm{OCH}_{3}^{+}(93 \mathrm{Th})$ reacts with 1,4-dioxane; (b) Reaction with a mixture of 1,4-dioxane and 1,4-dioxane- $d_{8}$ (1:1 by volume). One pair of doublet peaks, 137 and $141 \mathrm{Th}$, is observed.

An experiment has been carried out to test the possibility of detection of DMMP in a mixture without pre-separation, based on the net mass/charge gain in this novel selective ion/molecule reaction of $\mathrm{CH}_{3} \mathrm{P}(\mathrm{OH})\left(\mathrm{OCH}_{3}\right)_{2}^{+}$ions (125 Th) with 1,4-dioxane. In the experiment, 2, 2-dimethyl-3-pentanone, methyl trimethylacetate and $\mathrm{N}, \mathrm{N}$-diethyl propionamide were chosen as matrix components, representing ketone, ester and amide compounds. A mixture of 2, 2-dimethyl-3-pentanone, methyl trimethylacetate, DMMP, and

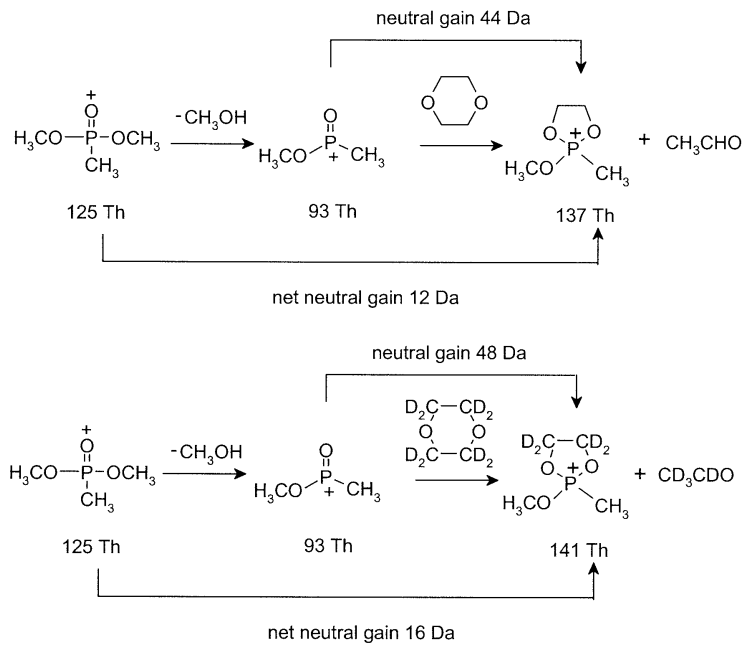

Scheme 3

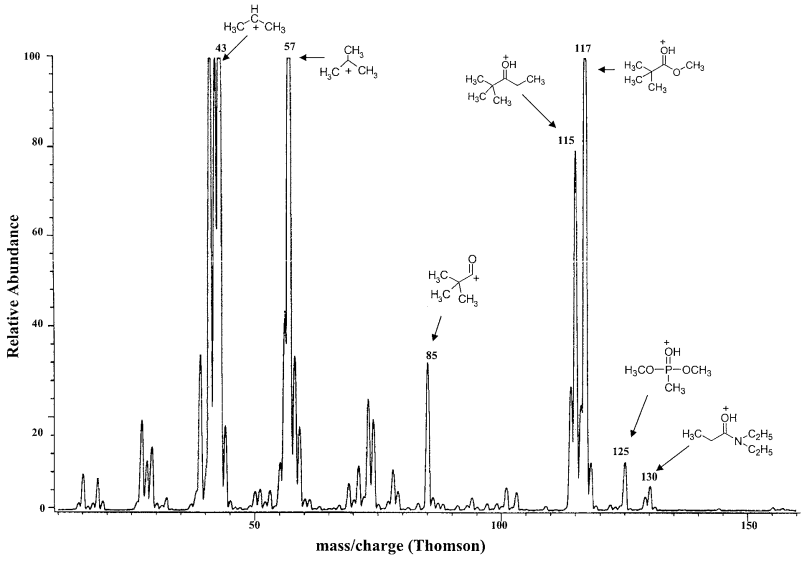

Figure 4. Isobutane CI mass spectrum of a mixture of 2, 2-dimethyl-3-pentanone, methyl trimethylacetate, DMMP, and $\mathrm{N}, \mathrm{N}$ diethyl propionamide. The $\left(\mathrm{CH}_{3}\right)_{2} \mathrm{CH}^{+}$ion (43 Th) behaves as the reagent ion.

$\mathrm{N}, \mathrm{N}$-diethyl propionamide was prepared in a volume ratio of 1:1:10:10. The mixture was introduced into the ion source via a leak valve and then ionized using isobutane as the reagent gas. All of the four compounds are protonated using isobutane chemical ionization (CI) and Figure 4 illustrates the isobutane $\mathrm{CI}$ mass spectrum of the mixture. The protonated molecular peaks of 2,2-dimethyl-3-pentanone, methyl trimethylacetate, DMMP, and N,N-diethyl propionamide are seen at 115 , 117,125 and $130 \mathrm{Th}$, respectively. A mixture of 1,4dioxane and 1,4-dioxane- $\mathrm{d}_{8}$ in 1:1 volume ratio was used as the neutral collision gas. Neutral gain MS/MS scans [41, 42] were employed with the mass/charge offset set as 12 or $16 \mathrm{Th}$. Q1 scanned ions in the range from 105 to $160 \mathrm{Th}$, which covered the protonated molecular ions of all four compounds. Simultaneously, Q3 was also scanned to record product ions at the same rate as Q1 scan. Neutral gain MS/MS scans provide the spectrum of precursor ions which undergo the ketalization reaction to form a product ion with the mass/ charge increment of 12 (or $16 \mathrm{Th}$ ). Figure $5 \mathrm{a}$ and $\mathrm{b}$ show the neutral gain scans and only the $\mathrm{CH}_{3} \mathrm{P}(\mathrm{OH})\left(\mathrm{OCH}_{3}\right)_{2}^{+}$ ion $(125 \mathrm{Th})$ is shown in both spectra. The protonated ions of 2,2-dimethyl-3-pentanone, methyl trimethylacetate and $\mathrm{N}, \mathrm{N}$-diethyl propionamide are not observed because they do not undergo ketalization with 1,4dioxane. This preliminary result demonstrates the potential feasibility of using the novel ketalization reaction as a means to detect DMMP in complex matrices.

The sensitivity of this detection method has also been examined. A $10 \mathrm{ppb}$ of DMMP solution (made up in $\left.\mathrm{H}_{2} \mathrm{O}: \mathrm{CH}_{3} \mathrm{OH}: \mathrm{CH}_{3} \mathrm{COOH}=200: 200: 1\right)$ was ionized by electrospray and then subject to a neutral gain MS/MS scan with the mass/charge offset of 12 Th using 1,4dioxane as the collision gas. Protonated DMMP (125 Th) was found to give a signal to noise ratio of greater than three. The detection limit is therefore in the low ppb range. This result is comparable to a previous report from this laboratory which analyzed DMMP using a 
(a)

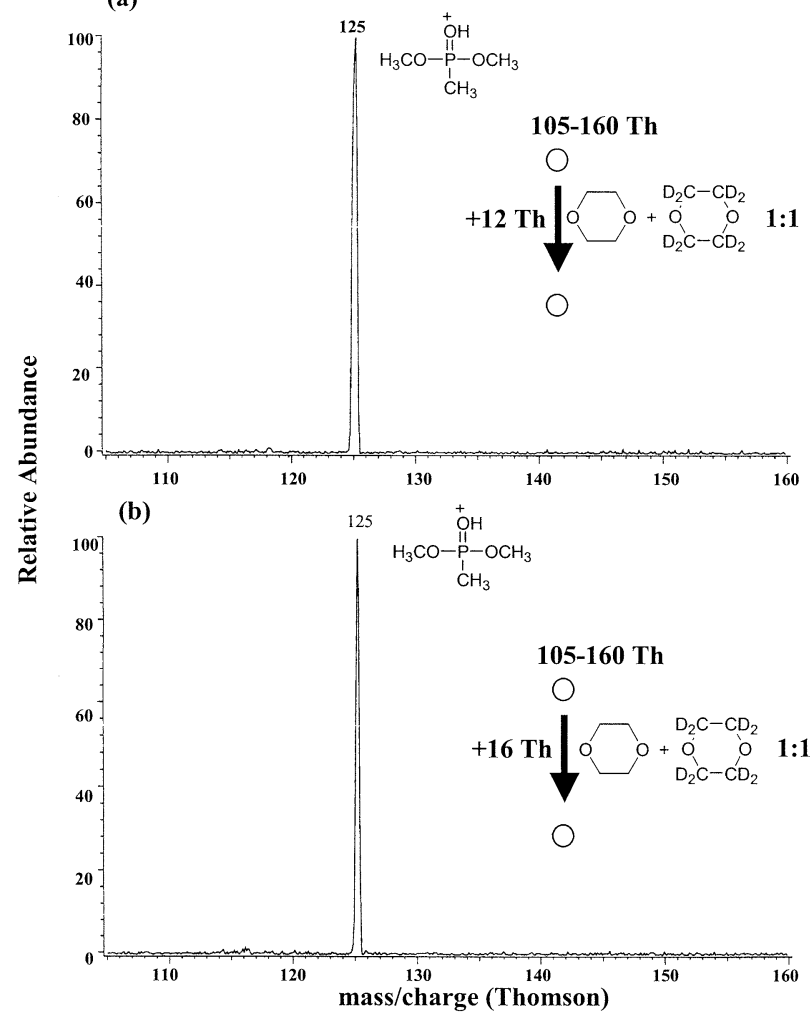

Figure 5. Constant neutral gain MS/MS spectra of a mixture of 2, 2-dimethyl-3-pentanone, methyl trimethylacetate, DMMP, and $\mathrm{N}, \mathrm{N}$-diethyl propionamide after isobutane chemical ionization. A mixture of 1,4-dioxane and 1,4-dioxane- $\mathrm{d}_{8}$ (1:1 by volume) is used as the neutral collision gas and Q1 is scanned from 105 to $160 \mathrm{Th}$. Q3 scans the corresponding product ions. The mass/charge offset is set as 12 Th in (a) and 16 Th in (b).

single-sided membrane introduction mass spectrometry and collision-induced dissociation [43].

A calibration curve with a good linearity $\left(\mathrm{r}^{2}=\right.$ 0.9992) in the concentration range of 10 to $500 \mathrm{ppb}$ has been obtained, illustrated in Figure 6. In these experiments we used aqueous samples because DMMP in air can be converted by preconcentration methods to provide aqueous solutions. In general, the detection of DMMP in mixtures using the novel ketalization reaction with 1,4-dioxane is highly selective and sensitive. This method is expected to be applicable to the selective

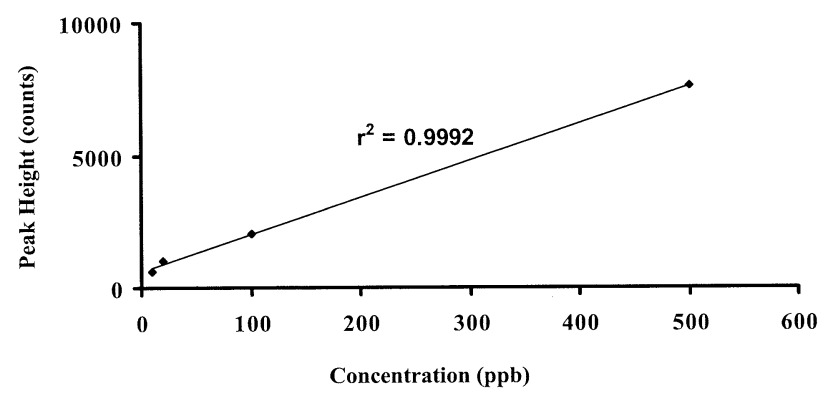

Figure 6. Calibration curve of DMMP showing the linearity of peak height versus concentration in the range of 10 to $500 \mathrm{ppb}\left(\mathrm{r}^{2}\right.$ $=0.9992$ ). detection of chemical warfare agents such as sarin in air and in water. Sarin gives a suitable phosphonium ion at 81 Th in its electron ionization mass spectrum although its reactivity has yet to be established [44].

\section{Conclusion}

The phosphonium ions $\mathrm{CH}_{3} \mathrm{P}(\mathrm{O}) \mathrm{OCH}_{3}^{+}$(93 Th) and $\mathrm{CH}_{3} \mathrm{OP}(\mathrm{O}) \mathrm{OCH}_{3}^{+}(109 \mathrm{Th})$ react with 1,4-dioxane to form characteristic ketalization product ions while many other ions such as acylium, iminium and carbosulfonium ions do not. The protonated DMMP ions also undergo the ketalization reaction after CID to give the phosphonium ion. The high selectivity of 1,4-dioxane to phosphonium ions is potentially important in the detection of chemical warfare agents since it excludes interference from various extraneous organic compounds such as ketones, esters, and amides in complex sample matrices. DMMP in the presence of 2, 2-dimethyl-3-pentanone, methyl trimethylacetate, and N,N-diethyl propionamide has been selectively identified using a constant neutral gain MS/MS scan without the sample pre-separation. The method has a detection limit in the low ppb range for aqueous solution. It appears that the selective ketalization of phosphonium ions by 1,4-dioxane has the potential to allow detection of chemical warfare agents in complex matrix by mass spectrometry.

\section{Acknowledgments}

This work was supported by ONR funding from the Office of Navy Research and the Integrated Detection of Hazardous Materials (IDHM) Program, Center for Sensing Science and Technology (Purdue University), and the Naval Surface Warfare Center (Crane, Indiana). The authors acknowledge Marcos Eberlin, Zheng Ouyang, and Pengxiang Yang for constructive suggestions.

\section{References}

1. Groenewold, G. S.; Todd, P. J. Detection of Gaseous Organophosphorus Compounds Using Secondary Ion Mass Spectrometry. Anal. Chem. 1985, 57, 886.

2. Ketkar, S. N.; Penn, S. M.; Fite, W. L. Influence of Coexisting Analytes in Atmospheric Pressure Ionization Mass Spectrometry. Anal. Chem. 1991, 63, 924.

3. Huang, M.-W.; Chei, H.-L.; Huang, J.-P.; Shiea, J. Application of Organic Solvents as Matrixes to Detect Air-Sensitive and Less Polar Compounds Using Low-Temperature Secondary Ion Mass Spectrometry. Anal. Chem. 1999, 71, 2901.

4. Agueera, A.; Contreras, M.; Crespo, J.; Fernandez-Alba, A. R. Multiresidue Method for the Analysis of Multiclass Pesticides in Agricultural Products by Gas Chromatography-Tandem Mass Spectrometry. Analyst 2002, 127, 347.

5. Charles, L.; Riter, L. S.; Cooks, R. G. Direct Analysis of Semivolatile Organic Compounds in Air by Atmospheric Pressure Chemical Ionization Mass Spectrometry. Anal. Chem. 2001, 73, 5061.

6. Schubert, H.; Guntow, U.; Hofmann, K.; Schloegl, R. Performance and Application Potential of Ion/Molecule Reaction Mass Spectrometry (IMR-MS) in the Analysis of Complex Gas Mixtures. Fresenius J. Anal. Chem. 1996, 356, 127. 
7. Brodbelt, J. S. Analytical Applications of Ion/Molecule Reactions. Mass Spectrom. Rev. 1997, 16, 91

8. Cooks, R. G.; Rockwood, A. L. The Thomson-A Suggested Unit for Mass Spectroscopists. Rapid Commun. Mass Spectrom. 1991, 5, 93.

9. Hodges, R. V.; McDonnell, T. J.; Beauchamp, J. L. Properties and Reactions of Trimethyl Phosphite, Trimethyl Phosphate, Triethyl Phosphate, and Trimethyl Phosphorothionate by Ion Cyclotron Resonance Spectroscopy. J. Am. Chem. Soc. 1980, 102, 1327.

10. Morizur, J.-P.; Gevrey, S.; Luna, A.; Taphanel, M.-H. GasPhase Ion/Molecule Reactions of Trimethyl Phosphite with the Phosphonium Ion $\mathrm{OP}\left(\mathrm{OCH}_{3}\right)^{2+}$ in a Quadrupole Ion Trap. J. Mass Spectrom. 1997, 32, 550.

11. Gevrey, S.; Luna, A.; Taphanel, M.-H.; Tortajada, J.; Morizur, J.-P. Experimental and Theoretical Studies of the Gas-Phase Reactivity of the $(\mathrm{HO})_{2} \mathrm{P}=\mathrm{O}^{+}$Phosphonium Ions towards Methanol. Int. J. Mass Spectrom. 2000, 195/196, 545.

12. Leclerc, E.; Buchmann, W.; Taphanel, M.-H.; Morizur, J.-P. Gas-Phase Ion/Molecule Reactions between Dimethoxyphosphonium Ions and Aromatic Hydrocarbons. Rapid Commun. Mass Spectrom. 2002, 16, 686.

13. Gal, J.-F.; Herreros, M.; Maria, P. C.; Operti, L.; Pettigiani, C.; Rabezzana, R.; Vaglio, G. A. Gas-Phase Ion/Molecule Reactions in Organophosphorus Esters. J. Mass Spectrom. 1999, 34, 1296.

14. Thoen, K. K.; Gao, L.; Ranatunga, T. D.; Vainiotalo, P.; Kenttämaa, H. I. Stereoselective Chemical Ionization Mass Spectrometry: Reactions of $\mathrm{CH}_{3} \mathrm{OPOCH}_{3}^{+}$with Cyclic Vicinal Diols. J. Org. Chem. 1997, 62, 8702.

15. Kenttämaa, H. I.; Cooks, R. G. Tautomer Characterization by Energy Resolved Mass Spectrometry. Dimethyl Phosphite and Dimethyl Phosphonate Ions. J. Am. Chem. Soc. 1985, 107, 1881.

16. Li, R.; Schweighofer, A.; Keck, H.; Kuchen, W.; Kenttämaa, H. I. The Radical Cation of Trimethylphosphine Oxide. Int. J. Mass Spectrom. Ion Processes 1996, 157/158, 293.

17. Zeller, L. Farrell, J., Jr.; Kenttämaa, H. I.; Vainiotalo, P. Long-Lived Radical Cations of Simple Organophosphates Isomerize Spontaneously to Distonic Structures in the Gas Phase. J. Am. Chem. Soc. 1992, 114, 1205.

18. Lum, R. C.; Grabowski, J. J. Carbon versus Phosphorus Site Selectivity in the Gas-Phase Anion/Molecule Reactions of Dimethyl Methylphosphonate. J. Am. Chem. Soc. 1993, 115, 7823.

19. Faye, T.; Mathurin, J. C.; Brunot, A.; Tabet, J. C. High-Pressure Ion Source Combined with an In-Axis Ion Trap Mass Spectrometer. 2. Application of Selective Low-Pressure Negative Ion Chemical Ionization. Anal. Chem. 2000, 72, 5063.

20. Steiner, V.; Daoust-Maleval, I.; Tabet, J.-C. Study of Gas-Phase Reactivity of Positive and Negative Even-Electron Ions Prepared from Diethylmethyl Phosphonate Ester in an External Chemical Ionization Source of Orthogonal Tandem Quadrupole/Ion Trap Instrument. Int. J. Mass Spectrom. 2000, 195/196, 121.

21. Wang, F.; Ma, S.; Tao, W. A.; Cooks, R. G. Replacement of C-O by $\mathrm{P}-\mathrm{O}$ in Cyclic Acetals and Ketals. Angew. Chem. Int. Ed. Engl. 1999, 38, 386.

22. Eberlin, M. N.; Cooks, R. G. Gas-Phase Oxirane to Acylium Ions on Reaction with 1,3-Dioxolanes Elucidated by Tandem and Triple Stage Mass Spectrometric Experiments. Org. Mass Spectrom. 1993, 28, 679.

23. Eberlin, M. N. Triple-Stage Pentaquadrupole (QqQqQ) Mass Spectrometry and Ion/Molecule Reactions. Mass Spectrom. Rev. 1997, 16, 113.

24. Moraes, L. A. B.; Pimpim, R. S.; Eberlin, M. N. Novel Ketalization Reaction of Acylium Ions with Diols and Analogues in the Gas Phase. J. Org. Chem. 1996, 61, 8726.

25. Moraes, L. A. B.; Mendes, M. A.; Sparrapan, R.; Eberlin, M. N. Transacetalization with Gaseous Carboxonium and Carbosulfonium Ions. J. Am. Soc. Mass Spectrom. 2001, 12, 14.
26. Moraes, L. A. B.; Eberlin, M. N. Ketalization of Gaseous Acylium Ions. J. Am. Soc. Mass Spectrom. 2001, 12, 150.

27. Moraes, L. A. B.; Gozzo, F. C.; Eberlin, M. N.; Vainiotalo, P. Transacetalization with Acylium Ions. A Structurally Diagnostic Ion/Molecule Reaction for Cyclic Acetals and Ketals in the Gas Phase. J. Org. Chem. 1997, 62, 5096.

28. Moraes, L. A. B.; Eberlin, M.N.; Marcos, N. Structurally Diagnostic Ion/Molecule Reactions: Acylium Ions with $\alpha-, \beta-$, and $\gamma$-Hydroxy Ketones. J. Mass Spectrom., 2002, 162.

29. Carvalho, M. C.; Juliano, V. F.; Kascheres, C.; Eberlin, M. N. Gas Phase Chemistry of the Heterocumulene Cations $\mathrm{O}=\mathrm{C}=\mathrm{N}^{+}=\mathrm{C}=\mathrm{O}$ and $\mathrm{O}=\mathrm{C}=\mathrm{C}=\mathrm{N}^{+}=\mathrm{O}$. J. Chem. Soc. Perkin Trans. 2 1997, 11, 2347.

30. Moraes, L. A. B.; Eberlin, M. N. Dehydrobenzoyl Cations: Distonic Ions with Dual Free Radical and Acylium Ion Reactivity. J. Am. Chem. Soc. 1998, 120, 11136.

31. Sparrapan, R.; Mendes, M. A.; Eberlin, M. N. Double Transacetalization of Diacylium Ions. J. Mass Spectrom. 2000, 35, 189.

32. Moraes, L. A. B.; Eberlin, M. N. Acyclic Distonic Acylium Ions: Dual Free Radical and Acylium Ion Reactivity in a Single Molecule. J. Am. Soc. Mass Spectrom. 2000, 11, 697.

33. Gozzo, F. C.; Sorrilha, A. E. P. M.; Eberlin, M. N. The Generation, Stability, Dissociation and Ion/Molecule Chemistry of Sulfinyl Cations in the Gas Phase. J. Chem. Soc. Perkin Trans. 2 1996, 4, 587.

34. Moraes, L. A. B.; Eberlin, M. N. Transacetalization of 1,3Dioxane with Acylium and Sulfinyl Cations in the Gas Phase. J. Chem. Soc. Perkin Trans. 2 1997, 10, 2015.

35. Tao, W. A.; Wang, F.; Denault, J. W.; Cooks, R. G. Synthesis of Silicon Heterocycles via Silylium Ion Reactions with Cyclic Acetals and Ketals. J. Chem. Soc. Perkin Trans. 2 1999, 11, 2325.

36. Wang, F.; Tao, W. A.; Gozzo, F. C.; Eberlin, M. N.; Cooks, R. G. Synthesis of B- and P-Heterocycles by Reaction of Cyclic Acetals and Ketals with Borinium and Phosphonium Ions. J. Org. Chem. 1999, 64, 3213.

37. Tao, W. A.; Zheng, X.; Cooks, R. G. Synthesis of B,N,OContaining Heterocycles via Eberlin Reaction of Dimethylamino Borinium Ion with Cyclic Acetals and Ketals. J. Mass Spectrom. 2000, 35, 1215.

38. Eberlin, M. N.; Morgon, N. H.; Yang, S. S.; Shay, B. J.; Cooks, R. G. Polar $[4+2+]$ Diels-Alder Cycloaddition to Nitrilium and Immonium Ions in the Gas Phase: Applications of Multiple Stage Mass Spectrometry in a Pentaquadrupole Instrument. J. Am. Soc. Mass Spectrom. 1995, 6, 1.

39. Bell, A. J.; Despeyroux, D.; Watts, J. M. P. Fragmentation and Reactions of Organophosphate Ions Produced by Electrospray Ionization. Int. J. Mass Spectrom. Ion Processes 1997, 165/166, 533.

40. McGall, G. H.; McClelland, R. A. Kinetics and Mechanism of the Hydrolysis of a $(5,6)$-Spirophosphorane. Thermodynamics of the Hydrolysis of Cyclic Five-Membered and Six-Membered Phosphonium Ions. Can. J. Chem. 1991, 69, 2064.

41. Cole, M. J.; Enke, C. G. Fast Atom Bombardment Tandem Mass Spectrometry Employing Ion/Molecule Reactions for the Differentiation of Phospholipid Classes. J. Am. Soc. Mass Spectrom. 1991, 2, 470.

42. Schwartz, J. C.; Wade, A. P.; Enke, C. G.; and Cooks, R. G. Systematic Delineation of Scan Modes in Multidimensional Mass Spectrometry. Anal. Chem. 1990, 62, 1809.

43. Riter, L. S.; Takats, Z.; Cooks, R. G. Single-Sided Membrane Introduction Mass Spectrometry for On-Line Determination of Semi-Volatile Organic Compounds in Air. Analyst 2001, 126, 1980.

44. McLafferty, F. W.; Stauffer, D. B. The Wiley/NBS Registry of Mass Spectral Data Vol. I. John Wiley and Sons, 1989, p 239. 